\title{
The Comparison between Chinese and western music education
}

\author{
Chunhua Chen ${ }^{1, a}$ \\ ${ }^{1}$ Shaanxi Xueqian Normal University, Xi'an, Shaanxi Province, China \\ a2481533218@qq.com
}

Keywords: Chinese and western music, Music style, Music education differences

\begin{abstract}
China has extensive and profound culture and music, Chinese and western music are in total different style. Both of them have their proud points. Chinese music is has a long history of culture accumulated rich experience in the Chinese nation, due to differences in regions, Chinese music is significantly different with the western classical music. This article summarize the different style of music between Chinese and western, and do the comparison between this two kinds of music education.
\end{abstract}

\section{Introduction}

Music is the blood of national emotion, is the soul of the culture will. As the saying goes, people is the most beautiful. As well as language, music with national and regional differences. Chinese music and western music is not only two big field of academic research, or professional music colleges and ordinary colleges and universities music professional required course. But as a result of Chinese and western music in the history content Jixi with the different cultural context, leads to the differences in both research and teaching [1]. This article will be compared and discussed, the right for us to explore the difference between Chinese and western music culture study and research of Chinese traditional music education thought and western music education ideas, absorbs the essence and remove dregs, establishing modern music education system, has important significance [1].

\section{The difference between Chinese and western music}

From the type of music, in the 20th century before the han Chinese culture, the types of music can be roughly divided into three different levels: the "official" to consolidate its central position of the interests of the political "yourself"; For folk, spread to the general public, to dissolve into the so-called "common", around by the han people's tone of voice, character and temperament and the influence of the local conditions and customs, showed the characteristics of the deep-themes: China "literati music", in music as the typical representative, pay attention to "is peace", the pursuit of "static far light virtual" state, its mental connotation tend to show a highly personal consciousness [2].

From the aspects of language, the language characteristics of music, Engels said that, you will only the national language, comparison with other languages can you truly understand your own language [2]. In recent years, ethnomusicology, through the method of linguistics began to notice in the music of different cultures, in different extent, embodies the difference between them and their language structure has a lot to do, they have their own music syntax structure. Compared with the western music, Chinese music has its own unique language, grammar, syntax structure, etc.

The style of Chinese music. Chinese music has thousands of years of history. Chinese music style characteristics of the first performance in the line of music, Chinese music and the music of linear thinking, give priority to in order to show tunes [2]. Second performance in harmony of music, music in our country gradually formed a kind of collective unconscious in the long-term practice, thus harmonious beauty as one of the important characteristics of music in China, the structure of exquisite balance, symmetry and smooth, in order to achieve an organic unity of inside and outside. Once again, the artistic conception of the music, including the pursuit of virtual and real and exquisite feeling.

The style of western music. Western music history roughly divided into ancient Greece period, in the middle ages, the Renaissance and baroque, classical and romantic period. From Gerry whatever led to the formation of the theory of modal notation way early discovery, on the basis of the chant 
development locate $\mathrm{Xu}$ [3], additional segments, as well as far-reaching polyphonic music, guido invention roll-call method, summed up the four-line stave, the development of western music, without rational spirit [3]. Westerners pursuit individual character liberation, see it as inviolable rights of the individual, in music and art, this is established on the basis of personality liberation of emotional performance won the vast heaven and earth, exclusive emotional performance of transition, dispassion, against the expansion of the subjective consciousness, advocates the objective and stable, and the Chinese music emphasizes "and" different, western music emphasizes the conflict.

\section{The Comparison between Chinese music and western music education}

Based on the above comparison and study of Chinese and western music, we can study the western music and explore the methods of our country's local music some thinking.

Education idea different. China's education ideas and education concept is very different in the United States, the biggest difference is: China favor force-feeding education [4]. The foundation of Chinese students is very solid, it's advantages, but also has faults, Chinese students face new things have cower psychology, and American students than up, innovative consciousness is poorer, whether all courses of study report, design or the internal structure of the school different this difference in the way that leads to the students are completely different. The internal structure of any institutions of higher learning are freely crisscross, the vertical direction is undergraduate course teaching, the direction of the cross is the study of science [4]. Different school its internal structure is not the same. Foreign first-class research university longitudinal concise, transverse rich; But the first-class higher vocational school longitudinal is rich, and lateral concise. But China's colleges and universities tend to be the same. For fudan or the school of Peking University, teaching the direction of not much, but the horizontal cross disciplines and research institutions can be more. But Chinese high school student was admitted to college, often divided into dozens of different department, school, like being led by narrow alleys, how can cultivate innovative talents? First-class research universities in the world, with the broad education in cultivating undergraduates first, put the professional training in a secondary.

The regional difference of education. Chinese and western because of the difference of regional, ethnic, and age music, so the Chinese music education and the western music education also exist differences [3]. Source of China's music education thought is Confucianism put forward by the two music education thought, is all in the spring and autumn period before the bud of music education point of view. The history of two thousand years of Chinese music education, has always been based on Confucianism, two music for the mainstream education thought. Both the pursuit of the harmony of music and nature,

The characteristic of the music education works differences. Chinese and western because of different way of thinking and different characteristics in the music. In short, China is "a tune multi-purpose - heavy hit; western for specialized music - original." "A song is multi-purpose" is based on respect for the original work's style and the original appreciation habits as value orientation, creation will be only a "fundamental tune" a little change, can give new connotation to the music. "Special" song, with the aim to pursue personality of the works, whether in the work of the form or on the writing techniques, are based on principles of not to repeat what others, don't repeat yourself [5].

Look from the creation of music works in the way, the creation of Chinese and western is also different. Works of traditional Chinese music creation way, has the collective, a thing or two degrees creation of oneness, etc. Collective, refers to the cohesion in the work of labor is not a composer's individual behavior [5]. A thing or two degrees creation of oneness, refers to the creation, the composer is singer or musician at a suit. Composing music at the same time, it is to sing or play process, not just a degree of division of labor, have extremely strong sex off the cuff. While western music works (mainly refers to the western professional composers as) way of creation, has the individuality, just a little creative separation characteristics. Western music works belongs to the composer for individual work, reflect the strong personality. At the same time, are separated on two degrees creation, namely the composer's creation only complete the sheet music. 
Aesthetic differences of music education. Aesthetic differences of music education. From the aesthetic idea to observe Chinese and western music we have found that Chinese music exquisite works of artistic conception, artistically, emphasizes the creation of gold, of character, pay attention to the performance of implicative, tactfully, be fond of art forms and moderate. While western music start with a strong religious influence and moral enlightenment color, relatively fixed form, often give a person a kind of solemn sacredness [6]. With the development of its own, the history of western music gradually join life and reality, the expression of feelings in straightforward, intense, has the strong ability of emotional expression. In the 20th century, the western music of bizarre phenomenon is already hard to understand and accept. However, the Chinese art song creation of Chinese poetry literature, Chinese folk songs and traditional European techniques, traditional Chinese music techniques, modern writing techniques organically unifies in together, formed a rich and colorful art song with Chinese national characteristics and style [6]. Moist European art world at this time by the Oriental culture and gradually infiltrated the European culture appeal and life, and the composer's interest in the Chinese music, began from the exotic and subject matter. Opened the western culture field of vision, open a wave "hot" Chinese culture.

Understand Chinese music. After understand and familiar with the Chinese national music, you can go to learn western advanced technology of harmony, melody, and the bands of the perfect [2], in China's own national characteristics, to enrich the Chinese national music, make the music of China in the true sense of progress, also make the Chinese and western music better dialogue, better fusion.

In general, western thinking is analytical, their music is by putting the maximum range development of music and sound the most complicate to represent the world. The Chinese thought has a comprehensive, in a small range within the scope of world.

Chinese music education. As a result of China's western music is the music style as the outline, writer works as the main content, therefore in western music history teaching, in addition to the historical, social, religious and other necessary background knowledge introduction, musician and music works is introduced, the appreciation has become one of the important content, but it is different from the aesthetic and spiritual pleasure to hearing not only for the purpose of music appreciation, but also different from the composition techniques from perspective of music analysis, is a kind of theory + appreciate + integrated curriculum, namely: by listening to music, make an analysis in terms of history [7]. In Chinese music history was different, because of the long long history, various reasons makes few retained the ancient music, not to mention music sound, therefore, only from the point of view of music works and music sound material the difference between Chinese and western music becomes obvious.

The difference between Chinese and western students. Foreign students' quality education is different from Chinese, they're more attention to students' individual character, especially the training of students' comprehensive quality and team spirit, and they do not like Chinese people especially on students' academic performance. A good high school does not mean that must produce how many master's and doctoral students [7]. According to statistics, China's third highest absolute number of graduate students has in the world, but 160000 annual salaries to somewhere recently hired senior skilled worker, but no one response. So, the establishment of a reasonable structure of colleges and universities, and make it conform to the law of education development, and can meet the different needs of society, it is very necessary.

The American higher education system, China's higher education system reform direction and goals. First of all, to improve the quality as the core task of the development of higher education, the basic requirement of higher education is the construction of power. Second, ensure the development of higher education science and the education quality steadily improved, also need to optimize structure characteristics [7]. Third, implement the scientific development of China's higher education, the need to recruit personnel training system, examination system, school running system, management system and so on deepening reform, perfect the modern university system, in colleges and universities teachers team construction, funds investment and so on to strengthen the guarantee of policy measures. At the same time, in order to achieve higher education career development goals, complete the tasks of various development, there is no necessary funding support and good system 
arrangement is simply not, also need the innovation system mechanism, strengthen policy measures to guarantee the respect such as move pace.

In brief, along with the increasing internationalization of cultural development, diversification, pursue the spirit of multi-level and high grade enjoyment has become a social fashion, fashion taste, elegant style of art song its aesthetic value gradually by the attention of people, making art songs in the spirit to enjoy space unprecedented prosperity. Because of the different social and cultural background, music creation technique and aesthetic differences, the Chinese art song creation is in collision with the European culture, blending the essence of western music at the same time, fully affirmed its aboriginality, while maintaining the original style on the basis of reference, the progress step by step.

\section{Conclusion}

In today's such a diverse world, cannot copy the western music education, also cannot be blindly praise highly touted the Chinese music and the negative advanced art achievements of western music. The center of the Chinese music and western music are naturally formed in the history of the development, it is not in the consciousness of the people, for transfer, the western music education of the dilemma even today is correct, not out of date. Western music education and the development of Chinese music education, has many places are worth to use for reference to Chinese music, but not just imitate the architecture of western music, but also grasp the essence. Chinese and western music education should learn from each other, promote each other, in order to achieve the common development.

\section{Acknowledgement}

This project, Research on the Development and Operation Mode of Art Music Theatre and Its Value in Shaanxi's Cultural Industry Chain, is supported by Social Science Funding of Shaanxi Province in 2015 (Projcet No.:2015J023).

\section{References}

[1] Q.H. Li, The western music history, Peking University press, 2002, pp.141-146.

[2] Y. Liu, Western classical music appreciation guidelines, Ningxia people's publishing house, 2005, pp.21-27.

[3] Zh.R.Xu, Classical music education in China, Hebei education publishing house, 2004, pp.77-82

[4] Z.Zh. Zeng, A comparative perspective of music teaching in the Chinese and western thinking, people's music, 2006, pp.21-28

[5] D.Y. Sun, The relevant thinking of western music history teaching, symphony, 1999, pp.63-67

[6] X.B. Hu, Research and teaching between China and western music art, East China normal university, 2005, pp.97-103.

[7] Y.Y. Zhou, Cultural perspectives of contemporary Chinese music teaching, East China normal university, 2013, pp.11-16. 